\title{
Effect of Evergreened Reformulations on Medicaid Expenditures and Patient Access from 2008 to 2016
}

\author{
Sean Dickson, JD, MPH
}

\begin{abstract}
BACKGROUND: Annual spending on retail and nonretail prescription drugs exceeds $\$ 450$ billion and is projected to outpace growth in all other national health expenditure categories over the next decade. Evergreened reformulations of drugs, defined here as extended-release or other reformulations that came to market more than 2 years after initial approval of the immediate-release product, increase drug spending and delay patient access to extended-release formulations. Reforming drug approval incentives may encourage earlier introduction of extended-release formulations, hastening generic adoption and patient access.
\end{abstract}

OBJECTIVES: To (a) systematically identify evergreened reformulations, defined as reformulations that extend drug exclusivity (i.e., extendedrelease or other reformulations that came to market more than 2 years after initial approval of the immediate-release product), and (b) estimate the effect on Medicaid spending and the delay in patient access to extendedrelease formulations.

METHODS: Evergreened reformulations were identified using FDA Orange Book drug approval data (1982-2018); these data were used to characterize mean time from initial brand approval to evergreen reformulation approval and subsequent generic approval. Medicaid expenditure data from 2008-2016 were used to estimate increased expenditures from delayed introduction of generic extended-release formulations. Outcome measurements include time from FDA approval of immediate-release brand drug to evergreened reformulation extended-release brand drug approval, annual generic share of immediate-release and extended-release prescriptions in Medicaid, and annual price difference between brand and generic prescriptions in Medicaid.

RESULTS: 73 drug active ingredients were subject to evergreened reformulations; these evergreened reformulations increased Medicaid expenditures by $\$ 9.35$ billion from 2008-2016. Among reformulations that increased expenditures by over $\$ 100$ million each, the mean time between the initial brand approval and evergreen reformulation approval was 8.1 years $(S D=3.9$; median = 8.8; interquartile range $[\mathrm{IQR}]=3.7-11.7)$; across all evergreened reformulations where the initial drug was approved after January 1,1982 , the mean was 7.9 years $(S D=4.3$; median $=6.8$; $\mathrm{IQR}=4.0-11.0)$.

CONCLUSIONS: Evergreened reformulations increase Medicaid drug expenditures and delay patient access to extended-release formulations. Reforming drug approval laws could alter market incentives for evergreened reformulations, decreasing spending and hastening patient access to extended-release products.

J Manag Care Spec Pharm. 2019;25(7):780-92

Copyright $\odot 2019$, Academy of Managed Care Pharmacy. All rights reserved.

\section{What is already known about this subject}

Expenditures on brand drugs are growing faster than other health sector expenditures

Drug manufacturers may engage in a variety of mechanisms, often called evergreening, that may extend the product life cycle for brand drugs.

Physicians and patients may prefer extended-release formulations of some medications, but these formulations are often introduced many years after the immediate-release formulation.

\section{What this study adds}

This study proposes a formal definition of evergreen reformulations, characterizes all drugs that meet this definition, and estimates the increased Medicaid spending and delayed patient access from evergreen reformulations.

This study offers tailored changes to drug approval laws that would discourage evergreen reformulations, decreasing spending and hastening patient access to extended-release formulations.

66 vergreening" is often cited as a cause of increased drug spending, but the term is poorly defined and no estimates of its effect on drug spending are available. ${ }^{1}$ Evergreening has been used to describe 3 different strategies to extend the market dominance of a brand drug: extending exclusivity through modifications to a delivery mechanism ("evergreen reformulations"), additional patents on the drug substance or delivery mechanism ("patent extensions"), and the introduction of changes to the structure of the molecule (e.g., chiral switch forms; "product hopping"). ${ }^{2-4}$ These 3 evergreening methodologies are all subject to different legal structures, requiring different policy solutions. In this study, we limit our focus to evergreen reformulations to rigorously define the scope of the problem and target solutions.

Although the term "evergreening" is often used pejoratively, the extended-release formulations considered to be evergreen reformulations herein often represent clinical improvements or are preferred by patients, as demonstrated by the market transition to the products observed in this study. While the development of an extended-release formulation requires additional resources and time, the delayed introduction of these formulations is often characterized as a product life cycle management technique rather than a result of dedicated efforts to introduce an improved product. ${ }^{5}$ 
In the introduction to a technical reference on the development of controlled-release formulations, the editors repeatedly cite life cycle management as the driver for introduction of an extended-release formulation, noting the life cycle benefits before patient benefits ("In addition to extending the patent life of those drugs whose patent protections are expiring, there are many other benefits for patients by using an oral controlled-release formulation") and describing the introduction of controlled-release formulations as a response to generic introduction ("Even though brand drug companies face huge pressure from generic companies, controlled-release formulation design is still a very useful tool in extending the life cycle for some drugs. For example, even though the drug substance of Ambien CR [Sanofi-Aventis], zolpidem tartrate, already lost patent protection, Ambien CR still garners sizeable revenue for the brand company"). ${ }^{6}$ This study does not assess whether the delayed introduction of an extendedrelease or other reformulation is driven by research and development barriers or life cycle management; instead, we assess how patient access and drug spending would differ if the reformulation were introduced earlier.

When a manufacturer delays introduction of a clinically or patient-preferred medication to extend a product's life cycle, this delays patient access to the preferred medication and the introduction of generic forms of the preferred product, increasing drug spending. Our analysis of evergreen reformulations characterizes the temporal delay between the introduction of the immediate-release and extended-release formulations-and the potential savings to the Medicaid program if the generic extended-release formulation were available at the same time as the generic immediate-release formulation-to highlight both the access and financial effects of this type of evergreening.

Extended- and controlled-release formulations have been consistently demonstrated to improve patient adherence to therapy and to be preferred by patients. A systematic review of patient adherence for chronic diseases found that switching from thrice-daily to once-daily dosing increased patients' adherent days by $22 \%-41 \%$, while switching from twice-daily to once-daily dosing increased adherent days by $13 \%-26 \%{ }^{7}$ Liver transplant patients who transitioned from twice-daily to once-daily dosing all reported that they preferred the oncedaily dosing; nonadherence dropped from $66 \%$ on the twicedaily regimen to $31 \%$ on the once-daily regimen. ${ }^{8}$ Patients with schizophrenia reported less sedation, higher overall treatment satisfaction, and milder side effects when taking an extended-release product rather than an instant-release product. ${ }^{9}$ Delayed introduction of clinically and patient-preferred formulations may have adverse clinical effects.

Evergreen reformulations are able to extend product life cycles because the evergreen reformulation may receive regulatory exclusivity even after all patent protections have elapsed. When a new active ingredient is initially approved as a drug by the U.S. Food and Drug Administration (FDA), it receives
5 years of exclusivity from generic competition ${ }^{10}$; a new delivery mechanism/reformulation for the same active ingredient would receive 3 years of exclusivity. ${ }^{11}$ Therefore, for purposes of this study, we proposed a narrow definition of evergreen reformulations: the introduction of new delivery mechanisms to the same active ingredient that increases FDA exclusivity beyond the initial term (i.e., mechanisms introduced more than 2 years after the product is first introduced). This allowed for the systematic identification of these drugs, assessment of the effects on drug spending, and the development of policy responses. Accordingly, we only considered a new delivery mechanism to be an evergreened drug when it was approved more than 2 years after the initial approval, as any approval before 2 years would not result in a period of exclusivity for the new product that extends beyond the FDA exclusivity granted to the original product, thus, maintaining the same exclusivity period for all formulations of the active ingredient (although patents may continue to block generic approvals).

Focusing on these new delivery mechanisms, notably extended- and delayed-release formulations, further allowed characterization of delayed patient access from delayed introduction of long-acting forms or preferred medications. From this definition, we analyzed the potential savings to the Medicaid program if generic versions of the evergreen reformulation had been available at the same time as generic versions of the initial formulation. Given that current drug approval regulatory structures may incentivize delayed introduction of reformulations to extend product life cycles, we also proposed changes to drug approval standards that would incentivize early introduction of extended-release formulations, improving patient access and decreasing spending.

\section{Methods}

\section{Evergreen Reformulation Identification and Data Source}

Evergreen reformulations were identified through the FDA Orange Book, which identifies therapeutically equivalent drugs. ${ }^{12}$ The Orange Book does not include biologic products, which are excluded from this analysis. To be considered an evergreen reformulation, we propose that a drug must meet 6 criteria. An evergreen reformulation is a drug (1) approved under a New Drug Application (NDA); (2) with the same active ingredients as a previously approved NDA; (3) by the same manufacturer as the previous drug or by another manufacturer but with the same base trade name; (4) more than 2 years after the previous drug ${ }^{13}$; (5) with either an extended-release, delayedrelease, or oral dissolving designation not shared with the previously approved drug; and (6) that is not an authorized generic Evergreen reformulations were identified at the NDA level.

For this analysis, evergreen reformulations were grouped with other drugs sharing the same active ingredients. Groups included all dosages and routes of administration for each active ingredients, and for descriptive purposes, the groups are named with the proprietary trade name of the first approved 
product; individual evergreen reformulations are referred to by their proprietary trade names (as the nonproprietary name is the same for each product within the group). Within each group, each drug was assigned to 1 of 4 categories: initial formulation, evergreened reformulation, generic initial formulation, and generic evergreened reformulation. The majority of evergreen reformulations identified were extended- or delayedrelease formulations (59 of 73).

Three evergreen drug groupings identified under this process (all identified through extended- or delayed-release reformulations with the same brand name) had additional reformulations that were manually identified as evergreen reformulations because they did not meet these criteria: Augmentin ES-600, a concentrated powder for oral suspension indicated for pediatric use within the Augmentin (amoxicillin clavulanate) group; Equetro and Carbatrol, extended-release capsules, within the Tegretol (carbamazepine) group; and Methylin, Methylin ER, Metadate CD, Metadate ER, Concerta, Aptensio XR, QuilliChew ER, and Quillivant ER, various methods of administration within the Ritalin (methylphenidate) group. These groupings and evergreen reformulations were manually identified because they included new brand products that captured substantial market share for the group more than 2 years after the first brand product was released; Augmentin ES-600 was not captured by the initial criteria because the route of administration was not included in the initial criterion even though it shared the same manufacturer and trade name, while the other products were made by different manufacturers and had different trade names. The manufacturer of Augmentin ES-600 notably characterizes its introduction in revenuefocused terms, indicating that the earlier formulation "has been experiencing increased competition in the USA ... and has lost patent protection in various countries in Europe." ${ }^{14}$ Results are presented with and without these manual additions.

Opana (oxymorphone hydrochloride) is also presented with 2 savings estimates. The manufacturer received an approval for oxymorphone hydrochloride in 1959 and marketed an immediate-release tablet until 1982; in 2006, the same manufacturer reintroduced tablets in both immediate- and extended-release formats. In 2011, the manufacturer introduced reformulated Opana ER (Opana ER-2011) with purported, but not FDArecognized, abuse-deterrent properties. ${ }^{15}$ We consider the 2006 introduction of Opana ER (Opana ER-2006) as an evergreen reformulation even though it was simultaneously introduced with a new immediate-release formulation; however, we separately present savings estimates from only considering Opana ER-2011 as the evergreen reformulation (the manufacturer removed the previous extended-release version from market after extended-release generic versions became available, preventing automatic generic substitution for prescriptions written for Opana ER-2011). ${ }^{16}$

\section{Medicaid Spending Data Source and Design}

The Medicaid Drug Utilization National Total datasets were used for prescription volume and cost; these data include all drug claims reimbursed by both fee-for-service and managed care Medicaid programs in each state, organized at the National Drug Code (NDC) level. ${ }^{17}$ This study was limited to 2008-2016 because of anomalies in the datasets for 2006 and 2007, which are likely due to duplicate claims from the Medicare Part D program. ${ }^{18}$ Utilization and spending data were summed at the NDC level for each year. NDCs were matched to FDA drug application numbers using the FDA NDC Structured Product Labeling Data Elements (NSDE) file. ${ }^{19}$ Application numbers were then used to link the utilization and spending data to the evergreen reformulation designations and product groupings from the FDA Orange Book. Under this methodology, 97\% of gross Medicaid overall drug expenditures during the period were matched to either FDA Orange Book data (86\%, representing all drugs) or FDA Purple Book data (11\%, representing all biologics). ${ }^{12,20}$ The Medicaid data include miscoded and old NDC numbers that are not included in the current NSDE file, resulting in reimbursement that was not matched to an FDA application number. All evergreen groups were matched to Medicaid spending data.

From this linking, annual market share was calculated for each initial formulation, evergreened reformulation, generic initial formulation, and generic evergreened reformulation subgroup as a percentage of total prescriptions within each active ingredient group. Annual spending for each formulation was used to calculate an average per-prescription cost for each formulation within each active ingredient group. The generic share of prescriptions for the initial formulation and the evergreened reformulation was calculated annually for each active ingredient group.

This analysis assumed that generic uptake would be the same for the initial formulation and the evergreened reformulation of the drug if a generic were available for each. Of the 17 evergreen groups in this analysis where both the generic initial formulations and generic evergreened reformulations were available for the entire 2008-2016 period, the mean rate ratio of generic substitution for the initial formulation to generic substitution for the evergreened reformulation in 2016 was 0.988 (standard deviation $[S D]=0.087$; median $=1.000$; interquartile range $[I Q R]=0.998-1.007)$, suggesting that generic substitution rates are similar for the initial formulation and evergreened reformulation when both have been available for a sustained period.

We estimated the annual foregone uptake of generic prescriptions for the evergreened reformulation by applying the annual generic share of initial formulation prescriptions to the number of evergreened reformulation prescriptions for that year and subtracting any generic evergreened reformulation prescriptions. For example, if there was $90 \%$ generic uptake of initial formulation prescriptions and no generic evergreened 


\section{TABLE 1 Identification of Evergreened Reformulations from the FDA Orange Book}

\begin{tabular}{|c|c|}
\hline Active ingredient groups assessed & 2,405 \\
\hline First product extended- or delayed-release tablet or capsule ${ }^{a}$ & 71 \\
\hline $\begin{array}{l}\text { Extended- or delayed-release tablet or capsule introduced } \\
\text { within } 2 \text { years }^{\mathrm{a}}\end{array}$ & 2 \\
\hline Evergreened reformulation introduced after 2 years & 73 \\
\hline Evergreened reformulation introduced between 2 and 3 years ${ }^{a}$ & 3 \\
\hline Evergreened reformulation introduced between 3 and 5 years ${ }^{\mathrm{a}}$ & 17 \\
\hline Evergreened reformulation introduced between 5 and 10 years $^{\mathrm{a}}$ & 20 \\
\hline Evergreened reformulation introduced more than 10 years ${ }^{a}$ & 18 \\
\hline $\begin{array}{l}\text { Evergreened active ingredient groups with Medicaid sales } \\
\text { 2008-2016 }\end{array}$ & 73 \\
\hline $\begin{array}{l}\text { Evergreened active ingredient groups with Medicaid sales of } \\
\text { evergreened reformulation 2008-2016 }\end{array}$ & 62 \\
\hline $\begin{array}{l}\text { Evergreened active ingredient groups with Medicaid sales of } \\
\text { generic initial formulation 2008-2016 }\end{array}$ & 53 \\
\hline $\begin{array}{l}\text { Evergreened active ingredient groups with potential Medicaid } \\
\text { savings 2008-2016 }\end{array}$ & 50 \\
\hline \multicolumn{2}{|c|}{$\begin{array}{l}\text { anly includes products where the initial formulation was approved after January } \\
1,1982 \text {, and the time between the initial formulation and the evergreened } \\
\text { reformulation could be calculated. } \\
\text { FDA =U.S. Food and Drug Administration. }\end{array}$} \\
\hline
\end{tabular}

reformulations were approved, we assumed that $90 \%$ of the evergreened reformulation prescriptions would have been generic had a generic been available. We then calculated the increased expenditures from delayed generic evergreened reformulation uptake by applying the difference in price between the evergreened reformulation brand drug per-prescription cost and the generic initial formulation drug per-prescription cost to the number of foregone generic evergreened reformulation prescriptions. This method is likely conservative, as Medicaid plans may allow for 90-day generic fills but only 30-day brand fills ${ }^{21}$; this would inflate the comparative per-prescription price of the generic initial formulation, underestimating increased expenditures.

\section{Statistical Analysis}

Descriptive statistics were used to characterize the mean time between initial formulation and evergreened reformulation approvals and generic approvals and estimated Medicaid savings. Analyses were performed in Stata, version 14.2 (StataCorp, College Station, TX).

\section{Results}

\section{Evergreen Reformulations}

From the FDA Orange Book, 2,405 active ingredient groups were assessed. Of these, 71 groups were initially launched after January 1, 1982, with an extended-release or delayed-release tablet or capsule as the first product. An additional 2 groups launched an extended-release or delayed-release tablet or capsule within 2 years of the initial product launch, which meant these products were not considered evergreen reformulations (Table 1).

From the FDA Orange Book, 74 active ingredient groups with possible evergreen reformulation groups were identified (Appendix A, available in online article). Of these 74 groups, 1 group, Nitro-Dur (nitroglycerin film, extended release), was manually excluded because the extended-release reformulation captured by the criteria had a different clinical application than the instant-release tablet; however, even when considering the film to be an evergreen reformulation, high generic uptake meant no savings were found in the period.

Of the 73 evergreen reformulation groups identified, 15 introduced the initial formulation before January 1 , 1982, the first date available in the Orange Book, rendering any calculation of the time from initial formulation to evergreened reformulation inaccurate. Of the remaining 58 groups, 3 introduced the evergreen reformulation within 3 years of initial formulation approval; 17 evergreened reformulations were introduced between 3 and 5 years after initial formulation approval; 20 evergreened reformulations were introduced between 5 and 10 years; and the remaining 18 evergreened reformulations were introduced more than 10 years after initial formulation approval (Table 1).

For these groups, the mean time from initial formulation approval to evergreened reformulation approval was 7.9 years $(\mathrm{SD}=4.3$; median $=6.8$; IQR=4.0-11.0). During this period, patients did not have access to any extended-release or other reformulation, either brand or generic. Of the 40 evergreened reformulations introduced before generic initial formulations, evergreened reformulations were introduced, on average, 4.2 years before generic initial formulation approval $(S D=3.7$; median =3.3; IQR = 1.3-5.2); 20\% (8) of evergreened reformulations were introduced less than 1 year before generic competition. Adderall, the evergreen group with the highest potential Medicaid savings (discussed below), introduced an extendedrelease reformulation only 4 months before a generic competitor for the immediate-release formulation was approved.

\section{Medicaid Savings}

Of the 73 evergreen reformulations identified, 11 had no sales of the branded evergreen reformulation during the 2008-2016 period; 2 products transitioned to over-the-counter formulations, while the remaining 9 discontinued the branded evergreen reformulation (Table 1). Because there were no sales of the branded evergreen reformulation during the period, no savings were available during the period.

Of the remaining 62 groups, 50 had increased expenditures attributable to delayed entry of the generic evergreened reformulation during the period (Table 1). Twelve groups did not have increased expenditures. In 9 of these groups, no generic (initial formulation or evergreened reformulation) was introduced during the period and therefore delayed generic evergreened reformulation uptake could not be estimated, while 


\begin{tabular}{|c|c|c|c|c|c|c|c|c|}
\hline $\begin{array}{l}\text { vergreen } \\
\text { roup }\end{array}$ & $\begin{array}{l}\text { Nonproprietary } \\
\text { Name }\end{array}$ & $\begin{array}{c}\text { Evergreen- } \\
\text { Increased } \\
\text { Expenditures, } \\
\$\end{array}$ & $\begin{array}{c}\text { Initial } \\
\text { Formulation } \\
\text { Approval }\end{array}$ & $\begin{array}{c}\text { Evergreened } \\
\text { Reformulation } \\
\text { Approval }\end{array}$ & \begin{tabular}{|c|} 
Initial \\
Formulation \\
to Evergreened \\
Reformulation \\
$\quad$ (Years) $^{\mathrm{a}}$
\end{tabular} & $\begin{array}{l}\text { Generic Initial } \\
\text { Formulation } \\
\text { Approval }\end{array}$ & $\begin{array}{c}\text { Generic } \\
\text { Evergreened } \\
\text { Reformulation } \\
\text { Approval }\end{array}$ & $\begin{array}{l}\text { Evergreened } \\
\text { Reformulation } \\
\text { to Generic } \\
\text { Initial } \\
\text { Formulation } \\
\text { (Years) }^{b}\end{array}$ \\
\hline Aderall & $\begin{array}{c}\text { Mixed } \\
\text { amphetamine salts }\end{array}$ & $2,679,301,216$ & $2 / 13 / 1996$ & $10 / 11 / 2001$ & 5.7 & $2 / 11 / 2002$ & $6 / 22 / 2012$ & 0.3 \\
\hline italin $^{c}$ & Methylphenidate & $2,132,604,620$ & Before $1 / 1 / 1982$ & $3 / 20 / 1982$ & NA & efore $1 / 1 / 1982$ & $6 / 1 / 1988$ & NA \\
\hline eroquel & Quetiapine & $1,752,368,048$ & 9/26/1997 & $5 / 17 / 2007$ & 9.6 & $3 / 27 / 2012$ & $11 / 1 / 2016$ & 4.9 \\
\hline ocalin & Dexmethylphenidate & $1,174,192,016$ & $11 / 13 / 2001$ & $5 / 26 / 2005$ & 3.5 & $1 / 29 / 2007$ & $8 / 28 / 2013$ & 1.7 \\
\hline amictal & Lamotrigine & $308,409,259$ & $12 / 27 / 1994$ & $5 / 8 / 2009$ & 14.4 & $6 / 21 / 2006$ & $12 / 26 / 2012$ & NA \\
\hline ffexor & Venlafaxine & $224,189,252$ & $12 / 28 / 1993$ & $10 / 20 / 1997$ & 3.8 & $8 / 3 / 2006$ & $6 / 28 / 2010$ & 8.8 \\
\hline Tegretold $^{\mathrm{d}}$ & Carbamazepine & $173,778,178$ & Before 1/1/1982 & $3 / 25 / 1996$ & $\mathrm{NA}$ & $5 / 15 / 1986$ & $3 / 31 / 2009$ & $\mathrm{NA}$ \\
\hline mbien & Zolpidem & $158,960,196$ & $12 / 16 / 1992$ & $9 / 2 / 2005$ & 12.7 & $4 / 23 / 2007$ & $10 / 13 / 2010$ & 1.6 \\
\hline eppra & Levetiracetam & $129,784,799$ & 11/30/1999 & $9 / 12 / 2008$ & 8.8 & $11 / 4 / 2008$ & $9 / 12 / 2011$ & 0.1 \\
\hline Abilifye & Aripiprazole & $123,966,354$ & $11 / 15 / 2002$ & $6 / 7 / 2006$ & 3.6 & $4 / 28 / 2015$ & $4 / 28 / 2015$ & 8.9 \\
\hline Opanaf & Oxymorphone & $108,642,027$ & Before $1 / 1 / 1982$ & $6 / 22 / 2006$ & $\mathrm{NA}$ & $6 / 14 / 2010$ & $6 / 14 / 2010$ & NA \\
\hline Wellbutrin & Bupropion & $103,117,155$ & $12 / 30 / 1985$ & 10/4/1996 & 10.8 & 11/29/1999 & $11 / 25 / 2003$ & 3.2 \\
\hline \multicolumn{9}{|c|}{$\begin{array}{l}\text { aWhen a formulation was approved before January 1, } 1982 \text { (as listed in the FDA Orange Book), no time between approvals can be accurately calculated. } \\
\text { bWhen the generic initial formulation was introduced before the evergreened reformulation, no time between approvals can be calculated. } \\
\text { c\$O possible savings without manual additions; evergreened reformulation approval date is for Ritalin-SR and does not include manual additions to the Ritalin group } \\
\text { specified in the Methods section; Ritalin LA was approved June 5, } 2002 \text {. } \\
\text { d\$28,186,595 possible savings without manual additions; evergreened reformulation approval date is for Tegretol-XR and does not include manual additions to the Tegretol } \\
\text { group specified in the Methods section. } \\
\text { ¿Evergreened reformulation approval date is for Abilify ODT; Abilify Maintena is also included in the group and was approved February 28, } 2013 \text {. } \\
\text { f\$79,712,849 possible savings when limited to Opana ER-2011; evergreened reformulation approval date is for Opana ER-2006; Opana ER-2011 was approved } \\
\text { December 9, } 2011 \text {. } \\
\text { FDA =U.S. Food and Drug Administration; NA=not applicable. }\end{array}$} \\
\hline
\end{tabular}

3 had no savings because the generic evergreened reformulation was introduced before the study period and generic evergreened reformulation uptake had already reached the same level as generic initial formulation uptake throughout the period.

From 2008 to 2016, Medicaid would have reduced gross expenditures on these 50 product groups by $\$ 9.35$ billion had generic evergreened reformulations been available at the same time and taken up at the same rate as generic initial formulations for the same active ingredient (Appendix B, available in online article). Over this period, this represents a $2.5 \%$ reduction in gross Medicaid outpatient drug expenditures, ranging from $2.0 \%$ of expenditures in 2015 and 2016 to 3.3\% of expenditures in 2010. Excluding the manually added evergreen reformulations specified in the Methods section, Medicaid would have reduced gross expenditures by $\$ 7.07$ billion, corresponding to $1.9 \%$ of gross outpatient drug expenditures.

\section{Descriptive Analysis of High-Savings Drugs}

Twelve drugs had evergreen-increased expenditures greater than $\$ 100$ million during the period, comprising $97 \%$ of all possible savings during the period (Table 2). Attention-deficit treatments (Adderall [mixed amphetamine salts], Ritalin [methylphenidate], andFocalin [dexmethylphenidate]) generated $64 \%$ of evergreen-increased expenditures. Mental health and antiepilepticdrugs (Seroquel [quetiapine], Lamictal [lamotrigine], Effexor [venlafaxine], Tegretol [carbamazepine], Keppra [levetiracetam], Abilify [aripiprazole], and Wellbutrin [bupropion]) generated an additional 30\% of evergreen-increased expenditures. Two additional drugs, Ambien (zolpidem) and Opana (oxymorphone), generated 3\% of evergreen-increased expenditures.

Among these 12 drugs, 9 introduced the evergreened reformulations before any generic (initial formulation or evergreened reformulation) was available (Ritalin, Lamictal, and Tegretol had generic initial formulations available before the evergreened reformulation was introduced). For these 9 drugs, the mean time between the initial formulation approval and evergreened reformulation approval was 8.1 years $(\mathrm{SD}=3.9 ;$ median = 8.8; $\mathrm{IQR}=3.7-11.7)$. 


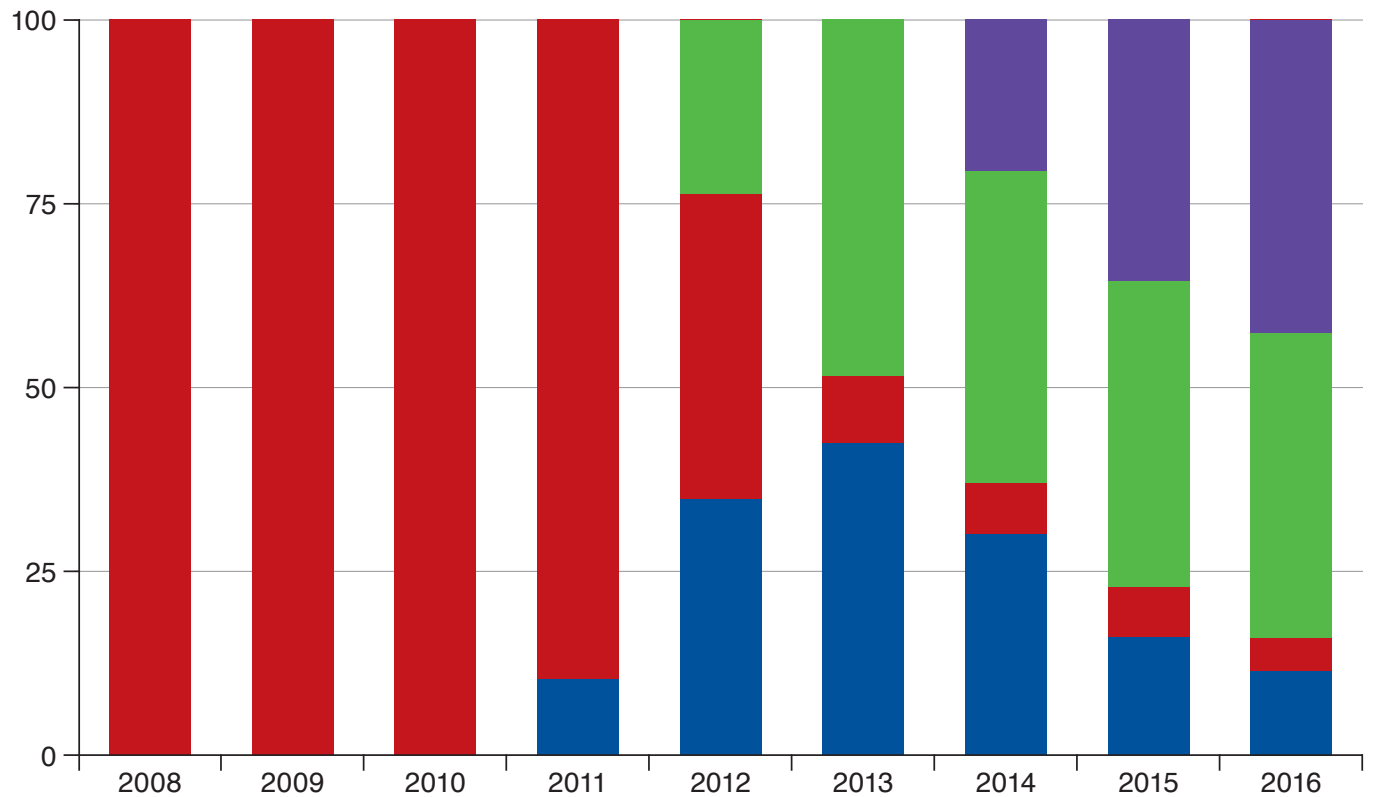

Note: The evergreened reformulation of Viramune (nevirapine) is estimated to have increased Medicaid expenditures by \$14 million during the study period. While Viramune had a lower financial impact than other drugs, its evergreened reformulation market share progression fully occurred within the study period and is presented as a general example of evergreened reformulation market share progression.

\section{Discussion}

Evergreened reformulations are encouraged by the current drug approval framework, delaying patient access to extended-release or other reformulations while increasing drug spending. While a manufacturer may desire to introduce a new product to the market as quickly as possible and therefore initially launch an immediate-release formulation, the current regulatory framework creates a market life cycle benefit for delaying the launch of a subsequent extended-release or other reformulation. The initial launch of an immediate-release formulation may also be driven by the desire for a less complex initial regulatory filing, but after that initial filing, manufacturers may be incentivized to delay seeking approval of the extended-release or other reformulation.

\section{FDA Approvals and Market Share over Time}

An evergreening strategy allows a manufacturer to retain market share by introducing the evergreened reformulation shortly before the expiration of patent or exclusivity protections for the initial formulation. The manufacturer would attempt to switch patients from the initial formulation (which will shortly face generic competition) to the evergreened reformulation (which will not) before a therapeutically equivalent generic initial formulation can be automatically substituted. Figures 1 and 2 provide graphical examples of this market life cycle transition using the annual share of initial formulation, evergreened reformulation, generic initial formulation, and generic evergreened reformulation of Medicaid sales for selected evergreened product groups.

The Food, Drug, and Cosmetic Act (FDCA) allows manufacturers to delay the introduction of evergreened reformulations in order to extend a product's life span. The FDCA has 2 approval pathwaysforbrand drugs:505(b)(1)and505(b)(2). ${ }^{22}$ The 505(b)(1) pathway is typically for new drugs and provides a manufacturer with 5 years of marketing exclusivity, during which time the FDA will not accept any generic applications. Under the 505(b)(2) pathway, a manufacturer may refer to studies submitted to the FDA under a previous 505(b)(1) application, reducing the complexity of studies that must be conducted. ${ }^{23}$ This approval pathway grants 3 years of exclusivity for the 505(b)(2) product if the manufacturer submits new studies as part of the application, such as extended-release product-dissolution studies. ${ }^{24} \mathrm{~A}$ manufacturer that has previously submitted a 505(b)(1) application can also submit a supplement to that application for a new formulation with the same active ingredient; if this supplement contains 


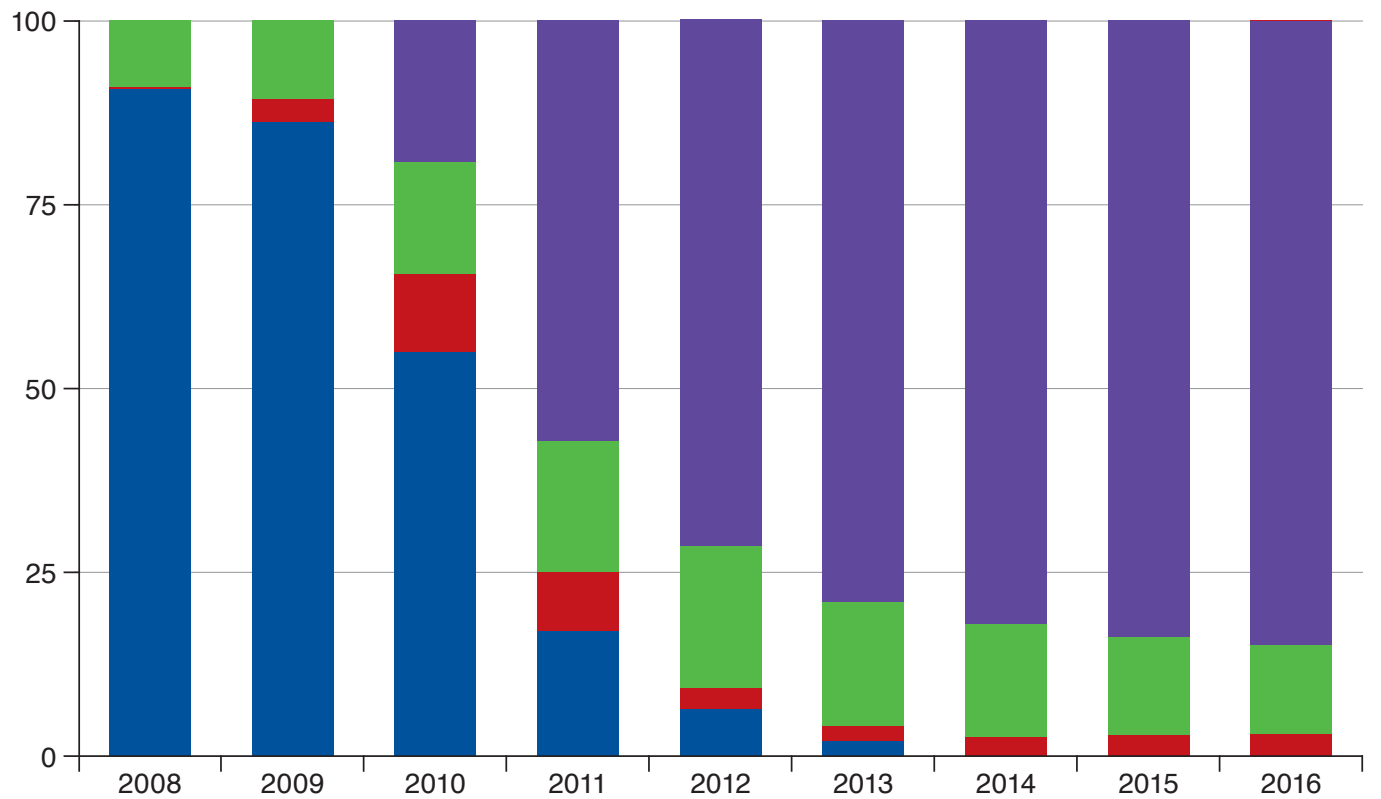

Initial formulation $\square$ Evergreened reformulation $\quad$ Generic initial formulation $\square$ Generic evergreened formulation

Note: The evergreened reformulation of Effexor (venlafaxine) is estimated to have increased Medicaid expenditures by $\$ 224$ million during the study period.

new studies, the manufacturer can receive an additional 3 years of exclusivity for the new formulation. ${ }^{24}$

The mean time from initial formulation approval to evergreened reformulation approval (7.9 years) exceeds the exclusivity granted under the 505(b)(1) application process. This suggests that manufacturers may wait until the expiration of patent protection, rather than FDA market exclusivity, to introduce an evergreened reformulation; patents are generally for 20 years but run from the start of product development, not FDA approval. ${ }^{24}$ While the time required to perform necessary approval studies for the evergreened reformulation may delay introduction, 20\% of evergreened reformulations in this analysis were introduced less than 1 year before the generic initial formulation was approved, suggesting that introduction of these evergreened reformulations may have been timed to patent expiration.

Some drugs, such as the antidepressants Effexor and Abilify and the antipsychotic Zyprexa, introduced extendedrelease reformulations earlier in the life cycle (Appendix A), perhaps to compete with extended-release formulations for therapeutically similar treatments. This suggests that manufacturers can develop extended-release products for some therapies relatively quickly and that market competition may drive earlier introduction of extended-release products. However, even in these instances, patients were without an extended-release option for nearly 4 years, with the introduction of the extended-release generic further delayed.

The $\$ 9.35$ billion of evergreen-increased expenditures for Medicaid from 2008-2016 identified here is a limited snapshot of the cost effect of evergreened reformulations. Assuming the same utilization patterns across all payers, this would equate to $\$ 62.04$ billion in higher expenditures for all payers based on national health expenditure (NHE) data from 2008-2016..$^{25}$ This estimate is conservative, as the NHE prescription drug spending data only include retail prescriptions and exclude spending on specialty pharmacy and physician-administered drugs, which are included in the Medicaid expenditure data. While rebates and other postsale discounts reduce net drug spending, the possible savings from earlier generic evergreened reformulation substitution likely remain substantial.

\section{Potential to Discourage Evergreened Reformulations, Hasten Extended-Release and Other Formulation Availability, and Reduce Expenditures}

Under the current framework, manufacturers have a frequent incentive to delay introducing extended-release or other formulations until patents and exclusivities for the initial formulation are near expiration. This results in higher drug expenditures and delayed patient access to extended-release or other formulations. 


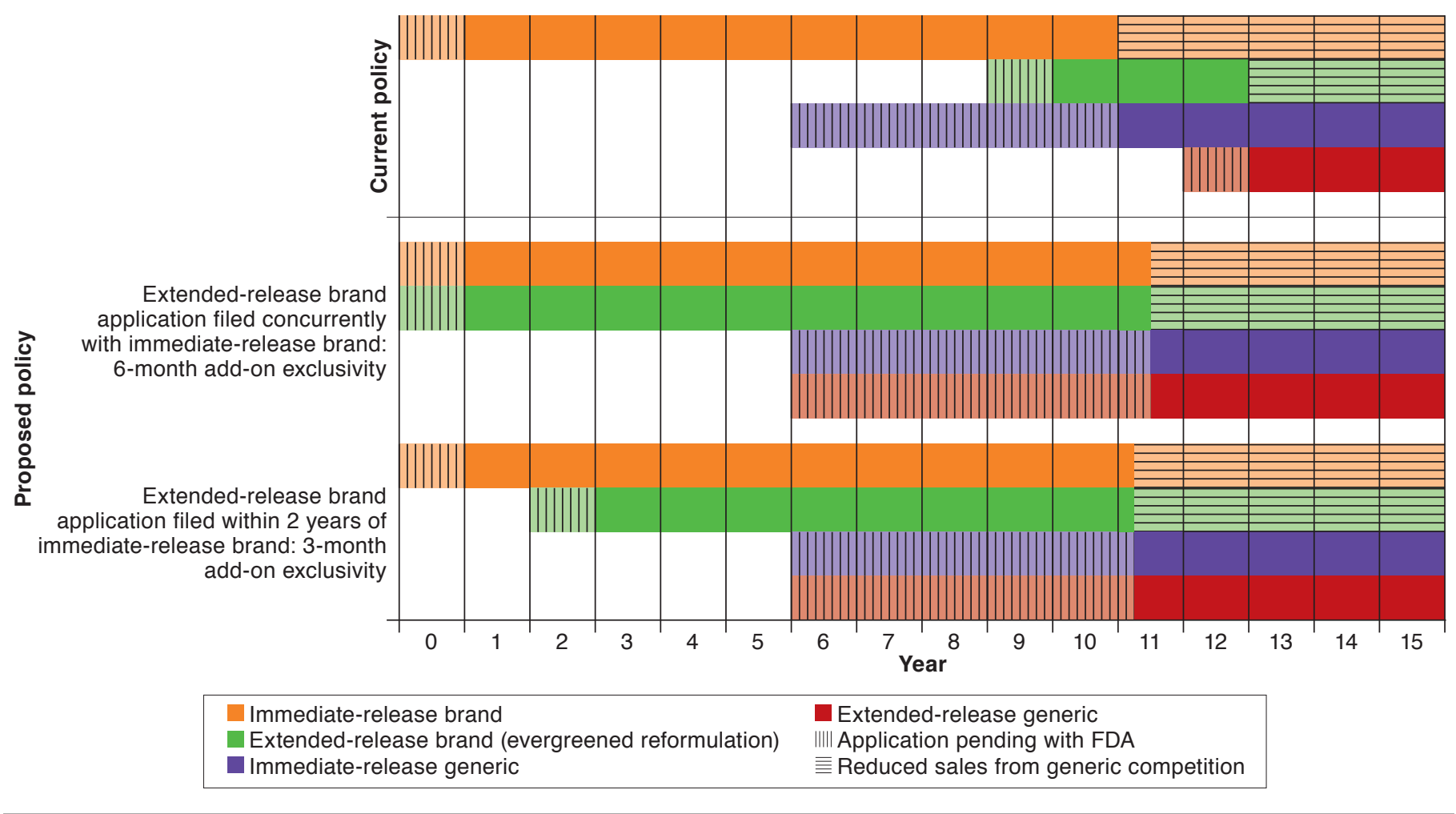

FDA =U.S. Food and Drug Administration.

Congress could discourage extended-release evergreened reformulations by revising the FDA approval system so that a manufacturer concurrently submitting both immediate- and extended-release formulations as part of an initial 505(b)(2) application would be eligible for a 6-month exclusivity add-on following expiration of all patents and other exclusivities; if the manufacturer submits an application for an extendedrelease formulation within 2 years of the initial application, the manufacturer would receive a 3-month exclusivity add-on. Congress would also need to revise the 505(b)(2) and 505(b)(1) supplement 3-year marketing exclusivity to eliminate additional exclusivity when the application is for an extended-release or other evergreen-style formulation of an existing product, eliminating the current incentive for delayed introduction. Figure 3 demonstrates immediate- and extended-release brand and generic availability under both the current regime and proposed reforms.

This policy would erode the benefit for delayed introduction of extended-release evergreened reformulations and provide incentives for early introduction. Policymakers should also consider the potential that the availability of additional exclusivity could incentivize the introduction of extendedrelease formulations that might not be introduced under the current system; this could produce both clinical benefits and added costs for those products.

Some precedent for this approach may be found in the current pediatric exclusivity policy, under which manufacturers that perform designated pediatric studies at a certain point in the product's life cycle receive an additional 6 months of exclusivity to encourage these studies. ${ }^{26}$ Importantly, this pediatric exclusivity applies only once all patent protection and other marketing exclusivity has expired; it will not be eclipsed by a long patent exclusivity.

\section{Limitations}

This study has several limitations in design. First, by focusing on a specific evergreening strategy, we did not identify the full set of drugs subject to evergreening strategies and their related increases in expenditures. Second, because Medicaid rebates are confidential, we only estimated the reduction in Medicaid pharmacy expenditures, not changes in net Medicaid spending. Third, because we limited our analysis to publicly available data, we were unable to directly estimate cost savings to Medicare or private insurers, which may have different utilization patterns. 
Additionally, this study did not consider the time and costs manufacturers incur in developing extended-release or other reformulations characterized as evergreen. While these costs may be significant, all manufacturers of products in this analysis chose to invest the resources in developing evergreened reformulations, presumably because market demand for these reformulations was sufficient to recoup costs. Realigned regulatory incentives that encourage earlier introduction of extended-release and other formulations may delay the introduction of the product line as a whole if manufacturers must expend additional time to complete extended-release or other studies earlier in the product's life cycle. The proposed 6-month additional exclusivity for the entire product line may also not be sufficient to encourage manufacturers to develop extended-release formulations if the additional revenues do not cover the costs of development.

\section{Conclusions}

Evergreened reformulations severely delay patient access to extended-release and other formulations. Manufacturer profits from evergreened reformulations, and the potential savings identified here, are all predicated on the idea that many patients and providers prefer extended-release and other formulations to instant-release formulations of drugs - if they do not, the subsequent low uptake would not generate significant profits or savings under current law. While this study did not evaluate the comparative benefits of extended- and immediate-release formulations, some research in attention-deficit disorder, where the majority of evergreen-increased expenditures are generated, suggests that patients see significant clinical benefit from access to extended-release formulations. ${ }^{27}$ This often overlooked aspect of evergreening and possible increased costs from lower adherence suggest clinical and financial benefits from reforming FDA drug approval protocols to discourage evergreened reformulations.

\section{Authors}

SEAN DICKSON, JD, MPH, Drug Spending Research Initiative, The Pew Charitable Trusts, Washington, DC.

AUTHOR CORRESPONDENCE: Sean Dickson, JD, MPH, Drug Spending Research Initiative, The Pew Charitable Trusts, 901 E St. N.W., Washington, DC 20004. Tel.: 202.540.6939;

E-mail:sdickson@pewtrusts.org.

\section{ACKNOWLEDGMENTS}

Allan J. Coukell and Ian S. Reynolds of The Pew Charitable Trusts critically reviewed the study proposal, assisted in interpreting findings, and contributed to reviewing and editing the manuscript.

\section{REFERENCES}

1. National Academies of Sciences, Engineering, and Medicine. Making Medicines Affordable: A National Imperative. Washington, DC: National Academies Press; 2018

2. Hitchings AW, Baker EH, Khong TK. Making medicines evergreen. BMJ. 2012;345:e7941

3. Hemphill CS, Sampat BN. Evergreening, patent challenges, and effective market life in pharmaceuticals. J Health Econ. 2012;31(2)327-39.

4. Beall RF, Nickerson JW, Kaplan WA, Attaran A. Is patent "evergreening" restricting access to medicine/device combination products? PLOS One. 2016;11(2):e0148939.

5. Dubey R, Dubey J. Pharmaceutical product differentiation: a strategy for strengthening product pipeline and life cycle management. J Med Marketing. 2009;9(2):104-18

6. Wen H, Park K. Introduction and overview of oral controlled release formulation design. In: Wen H, Park K, eds. Oral Controlled Release Formulation Design and Drug Delivery: Theory to Practice. Hoboken, NJ: John Wiley \& Sons; 2011:1-21.

7. Saini SD, Schoenfeld P, Kaulback K, Dubinsky MC. Effect of medication dosing frequency on adherence in chronic diseases. Am J Manag Care. 2009;15(6):e22-33.

8. Beckebaum S, Iacob S, Sweid D, et al. Efficacy, safety, and immunosuppressant adherence in stable liver transplant patients converted from a twice-daily tacrolimus-based regimen to once-daily tacrolimus extendedrelease formulation. Transpl Int. 2011;24(7):666-75.

9. Riedel M, Schmitz M, Østergaard PK, et al. Comparison of the effects of quetiapine extended-release and quetiapine immediate-release on cognitive performance, sedation and patient satisfaction in patients with schizophrenia: a randomised, double-blind, crossover study (eXtRa). Schizophr Res. 2015;162(1-3):162-68

10. Food, Drug, and Cosmetic Act. \$505(c)(3)(E)(ii). Available at: https://www. law.cornell.edu/uscode/text/21/355. Accessed February 19, 2019.

11. Food, Drug, and Cosmetic Act. \$505(c)(3)(E)(iii). Available at: https:// www.law.cornell.edu/uscode/text/21/355. Accessed February 19, 2019.

12. U.S. Food and Drug Administration. Approved drug products with therapeutic equivalence evaluations (Orange Book). Available at: https://www.fda. gov/Drugs/InformationOnDrugs/ucm129662.htm. Accessed February 5, 2019.

13. Hirani JJ, Rathod DA, Vadalia KR. Orally disintegrating tablets: a review. Trop J Pharm Res. 2009;8(2)161-72.

14. GlaxoSmithKline. Annual report 2001. 2002. Available at: https://www. gsk.com/media/2659/annual-report-2001.pdf. Accessed February 5, 2019

15. Jones CM, Lurie P, Woodcock J. Addressing prescription opioid overdose: data support a comprehensive policy approach. JAMA. 2014;312(17):1733-34.

16. Fields E. Regulatory history of Opana ER. Presented at Joint Meeting of the Drug Safety and Risk Management Advisory Committee and the Anesthetic and Analgesic Drug Products Advisory Committee. March 13-14, 2017. U.S. Food and Drug Administration. Available at: https://www.fda. gov/downloads/AdvisoryCommittees/CommitteesMeetingMaterials/Drugs/ AnestheticAndAnalgesicDrugProductsAdvisoryCommittee/UCM547235.pdf Accessed February 5, 2019.

17. Centers for Medicare \& Medicaid Services. State drug utilization data. Available at: https://www.medicaid.gov/medicaid/prescription-drugs/statedrug-utilization-data/index.html. Accessed February 5, 2019.
No outside funding supported this research. The author has no competing interests to disclose. 
18. Bruen BK, Miller LM. Changes in Medicaid prescription volume and use in the wake of Medicare Part D implementation. Health Aff (Millwood). 2008;27(1):196-202.

19. U.S. Food and Drug Administration. Comprehensive NDC SPL data elements file. Available at: https://www.fda.gov/ForIndustry/DataStandards/ StructuredProductLabeling/ucm240580.htm. Accessed February 5, 2019.

20. U.S. Food and Drug Administration. Purple Book: Lists of Licensed Biological Products with Reference Product Exclusivity and Biosimilarity or Interchangeability Evaluations. Available at: https://www.fda.gov/ drugs/developmentapprovalprocess/howdrugsaredevelopedandapproved/ approvalapplications/therapeuticbiologicapplications/biosimilars/ ucm411418.htm. Accessed February 19, 2019.

21. Iowa Department of Human Services. Iowa Medicaid PDL: billing/ quantity limits, Iowa Medicaid quantity limits effective October 1, 2018. Available at: http://www.iowamedicaidpdl.com/billing_quantity_limits. Accessed February 5, 2019.

22. Food, Drug, and Cosmetic Act. \$505(b). Available at: https://www.law. cornell.edu/uscode/text/21/355. Accessed February 19, 2019.
23. U.S. Food and Drug Administration, Center for Drug Evaluation and Research. Determining whether to submit an ANDA or a 505(b)(2) application: guidance for industry. 2017. Available at: https://www.fda.gov/ downloads/Drugs/GuidanceComplianceRegulatoryInformation/Guidances/ UCM579751.pdf. Accessed February 5, 2019.

24. U.S. Food and Drug Administration, Center for Drug Evaluation and Research. Patents and exclusivity. FDA/CDER SBIA Chronicles. May 19, 2015. Available at: https://www.fda.gov/downloads/drugs/ developmentapprovalprocess/smallbusinessassistance/ucm447307.pdf. Accessed February 5, 2019.

25. Centers for Medicare \& Medicaid Services. National health expenditure data. Available at: https://www.cms.gov/Research-Statistics-Data-andSystems/Statistics-Trends-and-Reports/NationalHealthExpendData/National HealthAccountsHistorical.html. Accessed February 5, 2019.

26. Food, Drug, and Cosmetic Act. §505A. Available at: https://www.law cornell.edu/uscode/text/21/355a. Accessed February 19, 2019.

27. Sikirica V, Xie J, He TL, Erde MH, Hodgkins P, Yang H. Immediaterelease versus extended-release guanfacine for treatment of attention-deficit/ hyperactivity disorder. Am J Pharm Benefits. 2013;5(4):e85-e94. 


\section{APPENDIX A Active Ingredients with Evergreened Reformulations, Dates of Approval, and} Time (Years) Between Approvals

\begin{tabular}{|c|c|c|c|c|c|c|c|}
\hline Trade Name & Active Ingredients & $\begin{array}{c}\text { Initial } \\
\text { Formulation } \\
\text { Approval }\end{array}$ & $\begin{array}{c}\text { Evergreened } \\
\text { Reformulation } \\
\text { Approval }\end{array}$ & $\begin{array}{c}\quad \text { Initial } \\
\text { Formulation } \\
\text { to Evergreened } \\
\text { Reformulation } \\
\text { (Years) }^{\mathrm{a}}\end{array}$ & $\begin{array}{l}\text { Generic Initial } \\
\text { Formulation } \\
\text { Approval }\end{array}$ & $\begin{array}{c}\text { Generic } \\
\text { Evergreened } \\
\text { Reformulation } \\
\text { Approval }\end{array}$ & $\begin{array}{l}\text { Evergreened } \\
\text { Reformulation } \\
\text { to Generic } \\
\text { Initial } \\
\text { Formulation } \\
\text { (Years) }^{b}\end{array}$ \\
\hline Naprosyn & Naproxen & Prior to $1 / 1 / 1982$ & $10 / 14 / 1994$ & $\mathrm{NA}$ & $10 / 30 / 1992$ & $2 / 18 / 1998$ & $\mathrm{NA}$ \\
\hline Sinemet & Carbidopa; levodopa & Prior to $1 / 1 / 1982$ & $5 / 30 / 1991$ & $\mathrm{NA}$ & $8 / 28 / 1992$ & 9/30/1999 & 1.2 \\
\hline Klonopin & Clonazepam & Prior to $1 / 1 / 1982$ & $12 / 23 / 1997$ & $\mathrm{NA}$ & 9/10/1996 & $8 / 3 / 2005$ & $\mathrm{NA}$ \\
\hline Flagyl & Metronidazole & Prior to $1 / 1 / 1982$ & $11 / 26 / 1997$ & $\mathrm{NA}$ & $11 / 6 / 1984$ & $6 / 25 / 2003$ & $\mathrm{NA}$ \\
\hline Xanax & Alprazolam & Prior to $1 / 1 / 1982$ & $1 / 17 / 2003$ & $\mathrm{NA}$ & $10 / 19 / 1993$ & $1 / 26 / 2006$ & NA \\
\hline Procardia & Nifedipine & Prior to $1 / 1 / 1982$ & 9/6/1989 & $\mathrm{NA}$ & $7 / 4 / 1990$ & $12 / 17 / 1999$ & 0.8 \\
\hline Inderal & Propranolol hydrochloride & Prior to $1 / 1 / 1982$ & $3 / 18 / 1987$ & $\mathrm{NA}$ & $7 / 30 / 1985$ & 4/11/1989 & $\mathrm{NA}$ \\
\hline Ditropan & Oxybutynin chloride & Prior to $1 / 1 / 1982$ & $12 / 16 / 1998$ & NA & $3 / 10 / 1988$ & $11 / 9 / 2006$ & NA \\
\hline Opanac & Oxymorphone hydrochloride & Prior to $1 / 1 / 1982$ & $6 / 22 / 2006$ & $\mathrm{NA}$ & $6 / 14 / 2010$ & $6 / 14 / 2010$ & 4.0 \\
\hline Tegretold & Carbamazepine & Prior to $1 / 1 / 1982$ & $3 / 25 / 1996$ & $\mathrm{NA}$ & $5 / 15 / 1986$ & $3 / 31 / 2009$ & NA \\
\hline Ritaline & Methylphenidate hydrochloride & Prior to $1 / 1 / 1982$ & $3 / 20 / 1982$ & $\mathrm{NA}$ & Prior to $1 / 1 / 1982$ & $6 / 1 / 1988$ & $\mathrm{NA}$ \\
\hline Inderide & $\begin{array}{c}\text { Hydrochlorothiazide; propranolol } \\
\text { hydrochloride }\end{array}$ & Prior to $1 / 1 / 1982$ & $7 / 3 / 1985$ & $\mathrm{NA}$ & $4 / 18 / 1986$ & & 0.8 \\
\hline Minipress & Prazosin hydrochloride & Prior to $1 / 1 / 1982$ & $1 / 29 / 1992$ & NA & 9/12/1988 & & $\mathrm{NA}$ \\
\hline Raniclor & Cefaclor & Prior to $1 / 1 / 1982$ & $6 / 28 / 1996$ & $\mathrm{NA}$ & Prior to $1 / 1 / 1982$ & $1 / 5 / 2001$ & NA \\
\hline Reglan & Metoclopramide hydrochloride & Prior to $1 / 1 / 1982$ & $6 / 10 / 2005$ & $\mathrm{NA}$ & $7 / 29 / 1985$ & $8 / 15 / 2014$ & $\mathrm{NA}$ \\
\hline Proventil & Albuterol sulfate & $5 / 7 / 1982$ & $7 / 13 / 1987$ & 5.2 & $12 / 5 / 1989$ & $9 / 26 / 2002$ & 2.4 \\
\hline Cardizem & Diltiazem hydrochloride & $11 / 5 / 1982$ & $1 / 23 / 1989$ & 6.2 & $11 / 5 / 1992$ & $11 / 30 / 1993$ & 3.8 \\
\hline Glucotrol & Glipizide & $5 / 8 / 1984$ & $4 / 26 / 1994$ & 10.0 & $5 / 10 / 1994$ & 9/8/2003 & $<0.1$ \\
\hline Augmentinf & Amoxicillin; clavulanate potassium & $8 / 6 / 1984$ & $6 / 22 / 2001$ & 16.9 & $3 / 14 / 2002$ & $4 / 21 / 2010$ & 0.7 \\
\hline Wellbutrin & Bupropion hydrochloride & $12 / 30 / 1985$ & 10/4/1996 & 10.8 & $11 / 29 / 1999$ & $11 / 25 / 2003$ & 3.2 \\
\hline Oruvail & Ketoprofen & $1 / 9 / 1986$ & 9/24/1993 & 7.7 & $12 / 22 / 1992$ & $12 / 10 / 1997$ & NA \\
\hline Pepcid & Famotidine & $10 / 15 / 1986$ & $5 / 28 / 1998$ & 11.6 & $4 / 16 / 2001$ & & 2.9 \\
\hline Prozac & Fluoxetine hydrochloride & $12 / 29 / 1987$ & $2 / 26 / 2001$ & 13.2 & $8 / 2 / 2001$ & $3 / 22 / 2010$ & 0.4 \\
\hline Cardene & Nicardipine hydrochloride & $12 / 21 / 1988$ & $2 / 21 / 1992$ & 3.2 & $7 / 18 / 1996$ & & 4.4 \\
\hline Rythmol & Propafenone hydrochloride & $11 / 27 / 1989$ & $9 / 4 / 2003$ & 13.8 & $10 / 24 / 2000$ & $10 / 18 / 2010$ & $\mathrm{NA}$ \\
\hline Cardura & Doxazosin mesylate & $11 / 2 / 1990$ & $2 / 22 / 2005$ & 14.3 & $10 / 18 / 2000$ & & $\mathrm{NA}$ \\
\hline Dynacirc & Isradipine & $12 / 20 / 1990$ & $6 / 1 / 1994$ & 3.4 & $1 / 5 / 2006$ & $11 / 27 / 2015$ & 11.6 \\
\hline Etodolac & Etodolac & $1 / 31 / 1991$ & $10 / 25 / 1996$ & 5.7 & $2 / 28 / 1997$ & $7 / 31 / 2000$ & 0.3 \\
\hline Videx & Didanosine & 10/9/1991 & $10 / 31 / 2000$ & 9.1 & $12 / 3 / 2004$ & $12 / 3 / 2004$ & 4.1 \\
\hline Biaxin & Clarithromycin & $10 / 31 / 1991$ & $3 / 3 / 2000$ & 8.3 & $5 / 25 / 2004$ & $6 / 24 / 2004$ & 4.2 \\
\hline Ambien & Zolpidem tartrate & $12 / 16 / 1992$ & $9 / 2 / 2005$ & 12.7 & $4 / 23 / 2007$ & $10 / 13 / 2010$ & 1.6 \\
\hline Paxil & Paroxetine hydrochloride & $12 / 29 / 1992$ & 2/16/1999 & 6.1 & $7 / 30 / 2003$ & $6 / 29 / 2007$ & 4.5 \\
\hline Propulsid & Cisapride monohydrate & $7 / 29 / 1993$ & $11 / 7 / 1997$ & 4.3 & & & $\mathrm{NA}$ \\
\hline Effexor & Venlafaxine hydrochloride & $12 / 28 / 1993$ & $10 / 20 / 1997$ & 3.8 & $8 / 3 / 2006$ & $6 / 28 / 2010$ & 8.8 \\
\hline Risperdal & Risperidone & $12 / 29 / 1993$ & $4 / 2 / 2003$ & 9.3 & $6 / 30 / 2008$ & $2 / 24 / 2009$ & 5.2 \\
\hline Lescol & Fluvastatin sodium & $12 / 31 / 1993$ & $10 / 6 / 2000$ & 6.8 & $4 / 11 / 2012$ & $9 / 11 / 2015$ & 11.5 \\
\hline Astagraf & Tacrolimus & 4/8/1994 & $7 / 19 / 2013$ & 19.3 & $8 / 10 / 2009$ & & $\mathrm{NA}$ \\
\hline Zerit & Stavudine & 6/24/1994 & $12 / 31 / 2002$ & 8.5 & $12 / 29 / 2008$ & & 6.0 \\
\hline Luvox & Fluvoxamine maleate & $12 / 5 / 1994$ & $2 / 28 / 2008$ & 13.2 & $11 / 29 / 2000$ & $3 / 13 / 2013$ & $\mathrm{NA}$ \\
\hline Lamictal & Lamotrigine & $12 / 27 / 1994$ & $5 / 8 / 2009$ & 14.4 & $6 / 21 / 2006$ & $12 / 26 / 2012$ & $\mathrm{NA}$ \\
\hline Glucophage & Metformin hydrochloride & $3 / 3 / 1995$ & $10 / 13 / 2000$ & 5.6 & $1 / 24 / 2002$ & $12 / 1 / 2003$ & 1.3 \\
\hline Ultram & Tramadol hydrochloride & $3 / 3 / 1995$ & $9 / 8 / 2005$ & 10.5 & $6 / 19 / 2002$ & $11 / 13 / 2009$ & $\mathrm{NA}$ \\
\hline Adderall & Mixed amphetamine salts & 2/13/1996 & $10 / 11 / 2001$ & 5.7 & $2 / 11 / 2002$ & $6 / 22 / 2012$ & 0.3 \\
\hline Remeron & Mirtazapine & $6 / 14 / 1996$ & $1 / 12 / 2001$ & 4.6 & $1 / 24 / 2003$ & $12 / 17 / 2003$ & 2.0 \\
\hline Viramune & Nevirapine & 6/21/1996 & $3 / 25 / 2011$ & 14.8 & $5 / 22 / 2012$ & $4 / 3 / 2014$ & 1.2 \\
\hline Allegra & Fexofenadine hydrochloride & $7 / 25 / 1996$ & $1 / 24 / 2011$ & 14.5 & $7 / 13 / 2005$ & $1 / 18 / 2013$ & NA \\
\hline Zyrtec & Cetirizine hydrochloride & 9/27/1996 & $9 / 3 / 2010$ & 13.9 & $12 / 27 / 2007$ & $9 / 2 / 2015$ & $\mathrm{NA}$ \\
\hline Zyprexa & Olanzapine & 9/30/1996 & $4 / 6 / 2000$ & 3.5 & $10 / 24 / 2011$ & $10 / 24 / 2011$ & 11.6 \\
\hline
\end{tabular}




\begin{tabular}{|c|c|c|c|c|c|c|c|}
\hline Trade Name & Active Ingredients & $\begin{array}{c}\text { Initial } \\
\text { Formulation } \\
\text { Approval }\end{array}$ & $\begin{array}{l}\text { Evergreened } \\
\text { Reformulation } \\
\text { Approval }\end{array}$ & $\begin{array}{c}\text { Initial } \\
\text { Formulation } \\
\text { to Evergreened } \\
\text { Reformulation } \\
\text { (Years) }^{\mathrm{a}}\end{array}$ & $\begin{array}{l}\text { Generic Initial } \\
\text { Formulation } \\
\text { Approval }\end{array}$ & $\begin{array}{c}\text { Generic } \\
\text { Evergreened } \\
\text { Reformulation } \\
\text { Approval } \\
\end{array}$ & $\begin{array}{l}\text { Evergreened } \\
\text { Reformulation } \\
\text { to Generic } \\
\text { Initial } \\
\text { Formulation } \\
\text { (Years) }^{\mathrm{b}}\end{array}$ \\
\hline Aricept & Donepezil hydrochloride & $11 / 25 / 1996$ & $10 / 18 / 2004$ & 7.9 & $12 / 11 / 2009$ & $12 / 11 / 2009$ & 5.2 \\
\hline Zyflo & Zileuton & $12 / 9 / 1996$ & $5 / 30 / 2007$ & 10.5 & $3 / 17 / 2017$ & $3 / 17 / 2017$ & 9.8 \\
\hline Mirapex & Pramipexole dihydrochloride & 7/1/1997 & $2 / 19 / 2010$ & 12.6 & $2 / 19 / 2008$ & $2 / 6 / 2014$ & NA \\
\hline Requip & Ropinirole hydrochloride & 9/19/1997 & $6 / 13 / 2008$ & 10.7 & $5 / 5 / 2008$ & $5 / 17 / 2012$ & NA \\
\hline Seroquel & Quetiapine fumarate & 9/26/1997 & $5 / 17 / 2007$ & 9.6 & $3 / 27 / 2012$ & $11 / 1 / 2016$ & 4.9 \\
\hline Zomig & Zolmitriptan & $11 / 25 / 1997$ & $2 / 13 / 2001$ & 3.2 & $5 / 14 / 2013$ & $5 / 14 / 2013$ & 12.3 \\
\hline Detrol & Tolterodine tartrate & $3 / 25 / 1998$ & $12 / 22 / 2000$ & 2.7 & $9 / 25 / 2012$ & $10 / 31 / 2013$ & 11.8 \\
\hline Atelvia & Risedronate sodium & $3 / 27 / 1998$ & $10 / 8 / 2010$ & 12.5 & $10 / 5 / 2007$ & $5 / 18 / 2015$ & NA \\
\hline Keppra & Levetiracetam & $11 / 30 / 1999$ & 9/12/2008 & 8.8 & $11 / 4 / 2008$ & 9/12/2011 & 0.1 \\
\hline Razadyne & Galantamine hydrobromide & $2 / 28 / 2001$ & $4 / 1 / 2005$ & 4.1 & $8 / 28 / 2008$ & 9/15/2008 & 3.4 \\
\hline Focalin & Dexmethylphenidate hydrochloride & $11 / 13 / 2001$ & $5 / 26 / 2005$ & 3.5 & $1 / 29 / 2007$ & $8 / 28 / 2013$ & 1.7 \\
\hline Clarinex & Desloratadine & $12 / 21 / 2001$ & $7 / 14 / 2005$ & 3.6 & $2 / 19 / 2010$ & $7 / 12 / 2010$ & 4.6 \\
\hline Abilifyg & Aripiprazole & $11 / 15 / 2002$ & $6 / 7 / 2006$ & 3.6 & $4 / 28 / 2015$ & $4 / 28 / 2015$ & 8.9 \\
\hline Staxyn & Vardenafil hydrochloride & $8 / 19 / 2003$ & $6 / 17 / 2010$ & 6.8 & $5 / 3 / 2012$ & & 1.9 \\
\hline Namenda & Memantine hydrochloride & $10 / 16 / 2003$ & $6 / 21 / 2010$ & 6.7 & $4 / 14 / 2010$ & 9/28/2016 & NA \\
\hline Sanctura & Trospium chloride & $5 / 28 / 2004$ & $8 / 3 / 2007$ & 3.2 & $8 / 13 / 2010$ & $10 / 12 / 2012$ & 3.0 \\
\hline Bydureon & Exenatide synthetic & $4 / 28 / 2005$ & $1 / 27 / 2012$ & 6.8 & & & NA \\
\hline Actoplus MET & $\begin{array}{l}\text { Metformin hydrochloride; } \\
\text { pioglitazone hydrochloride }\end{array}$ & $8 / 29 / 2005$ & $5 / 12 / 2009$ & 3.7 & $2 / 25 / 2011$ & & 1.8 \\
\hline Noxafil & Posaconazole & $9 / 15 / 2006$ & $11 / 25 / 2013$ & 7.2 & & & NA \\
\hline Janumet & $\begin{array}{l}\text { Metformin hydrochloride; } \\
\text { sitagliptin phosphate }\end{array}$ & $3 / 30 / 2007$ & $2 / 2 / 2012$ & 4.8 & & & NA \\
\hline Nucynta & Tapentadol hydrochloride & $11 / 20 / 2008$ & $8 / 25 / 2011$ & 2.8 & & & NA \\
\hline Jentadueto & $\begin{array}{l}\text { Linagliptin; metformin } \\
\text { hydrochloride }\end{array}$ & $1 / 30 / 2012$ & $5 / 27 / 2016$ & 4.3 & & & NA \\
\hline Belviq & Lorcaserin hydrochloride & $6 / 27 / 2012$ & $7 / 15 / 2016$ & 4.1 & & & NA \\
\hline Xeljanz & Tofacitinib citrate & $11 / 6 / 2012$ & $2 / 23 / 2016$ & 3.3 & & & NA \\
\hline Invokamet & $\begin{array}{l}\text { Canagliflozin; metformin } \\
\text { hydrochloride }\end{array}$ & $8 / 8 / 2014$ & $9 / 20 / 2016$ & 2.1 & & & NA \\
\hline
\end{tabular}

aWhen a formulation was approved before January 1, 1982 (as listed in the FDA Orange Book), no time between approvals can be accurately calculated.

${ }^{b}$ When the generic initial formulation was introduced before the evergreened reformulation, no time between approvals can be calculated.

'Evergreened reformulation approval date is for Opana ER-2006; Opana ER-2011 was approved December 9, 2011.

dEvergreened reformulation approval date is for Tegretol-XR and does not include manual additions to the Tegretol group specified in the Methods section.

'Evergreened reformulation approval date is for Ritalin-SR and does not include manual additions to the Ritalin group specified in the Methods section; Ritalin LA was approved June 5, 2002.

fEvergreened reformulation approval date is for Augmentin ES-600, a manual addition described in the Methods section; Augmentin XR was approved September $25,2002$.

gEvergreened reformulation approval date is for Abilify ODT; Abilify Maintena is also included in the group and was approved February $28,2013$.

FDA =U.S. Food and Drug Administration; NA=not applicable. 
Effect of Evergreened Reformulations on Medicaid Expenditures and Patient Access from 2008 to 2016

\begin{tabular}{|c|c|c|c|c|c|}
\hline \multicolumn{6}{|c|}{ APPENDIX B } \\
\hline $\begin{array}{l}\text { Trade } \\
\text { Name }\end{array}$ & Active Ingredients & $\begin{array}{l}\text { Estimated Savings, } \\
\$\end{array}$ & $\begin{array}{l}\text { Trade } \\
\text { Name }\end{array}$ & Active Ingredients & $\begin{array}{l}\text { Estimated Savings, } \\
\$\end{array}$ \\
\hline Adderall & Mixed amphetamine salts & $2,679,301,216$ & Pepcid & Famotidine & NA; transitioned to OTC \\
\hline Ritalina $^{\mathrm{a}}$ & Methylphenidate hydrochloride & $2,132,604,620$ & \multirow{2}{*}{$\begin{array}{l}\text { Zyrtec } \\
\text { Allergy }\end{array}$} & \multirow[t]{2}{*}{ Cetirizine hydrochloride } & \multirow[t]{2}{*}{ NA; transitioned to OTC } \\
\hline Seroquel & Quetiapine fumarate & $1,752,368,048$ & & & \\
\hline Focalin & Dexmethylphenidate hydrochloride & $1,174,192,016$ & \multirow[t]{2}{*}{ Invokamet } & \multirow{2}{*}{$\begin{array}{l}\text { Canagliflozin; metformin } \\
\text { hydrochloride }\end{array}$} & \multirow[t]{2}{*}{ NA; no generic in period } \\
\hline Lamictal & Lamotrigine & $308,409,259$ & & & \\
\hline Effexor & Venlafaxine hydrochloride & $224,189,252$ & Nucynta & Tapentadol hydrochloride & NA; no generic in period \\
\hline Tegretolb $^{\mathrm{b}}$ & Carbamazepine & $173,778,178$ & Xeljanz & Tofacitinib citrate & NA; no generic in period \\
\hline Ambien & Zolpidem tartrate & $158,960,196$ & Belviq & Lorcaserin hydrochloride & NA; no generic in period \\
\hline Keppra & Levetiracetam & $129,784,800$ & \multirow[t]{2}{*}{ Jentadueto } & \multirow{2}{*}{$\begin{array}{l}\text { Linagliptin; metformin } \\
\text { hydrochloride }\end{array}$} & \multirow[t]{2}{*}{ NA; no generic in period } \\
\hline Abilifyc & \begin{tabular}{|l|} 
Aripiprazole \\
\end{tabular} & $123,966,354$ & & & \\
\hline Opanad & Oxymorphone hydrochloride & $108,642,027$ & \multirow[t]{2}{*}{ Janumet } & \multirow{2}{*}{$\begin{array}{l}\text { Metformin hydrochloride; } \\
\text { sitagliptin phosphate }\end{array}$} & \multirow[t]{2}{*}{ NA; no generic in period } \\
\hline Wellbutrin & Bupropion hydrochloride & $103,117,155$ & & & \\
\hline Zyprexa & Olanzapine & $57,981,706$ & Bydureon & Exenatide synthetic & NA; no generic in period \\
\hline Risperdal & Risperidone & $42,993,610$ & Noxafil & Posaconazole & NA; no generic in period \\
\hline Paxil & Paroxetine hydrochloride & $37,434,960$ & Zyflo & Zileuton & NA; no generic in period \\
\hline Ultram & Tramadol hydrochloride & $21,805,597$ & \multirow{4}{*}{ Glucophage } & \multirow[t]{4}{*}{ Metformin hydrochloride } & \multirow{4}{*}{$\begin{array}{l}\text { NA; generic evergreened } \\
\text { reformulation uptake same } \\
\text { or greater than generic } \\
\text { initial formulation uptake }\end{array}$} \\
\hline Luvox & Fluvoxamine maleate & $20,636,378$ & & & \\
\hline Viramune & Nevirapine & $14,051,796$ & & & \\
\hline Detrol & Tolterodine tartrate & $13,689,773$ & & & \\
\hline Cardizem & Diltiazem hydrochloride & $12,799,990$ & \multirow[t]{4}{*}{ Staxyn } & \multirow[t]{4}{*}{ Vardenafil hydrochloride } & \multirow{4}{*}{$\begin{array}{l}\text { NA; generic evergreened } \\
\text { reformulation uptake same } \\
\text { or greater than generic } \\
\text { initial formulation uptake }\end{array}$} \\
\hline Ditropan & Oxybutynin chloride & $10,957,609$ & & & \\
\hline Namenda & Memantine hydrochloride & $10,061,688$ & & & \\
\hline Augmentin & Amoxicillin; clavulanate potassium & $8,101,425$ & & & \\
\hline Prozac & Fluoxetine hydrochloride & $3,888,886$ & \multirow[t]{3}{*}{ Videx } & Didanosine & NA; generic evergreened \\
\hline Rythmol & Propafenone hydrochloride & $3,671,474$ & & & reformulation uptake same \\
\hline Inderal & Propranolol hydrochloride & $3,247,171$ & & & $\begin{array}{l}\text { or greater than generic } \\
\text { initial formulation uptake }\end{array}$ \\
\hline Mirapex & Pramipexole dihydrochloride & $2,662,932$ & Inderide & & \\
\hline Procardia & Nifedipine & $2,659,934$ & Inderide & $\begin{array}{l}\text { Hyarochiorothiazide; } \\
\text { propranolol hydrochloride }\end{array}$ & reformulation \\
\hline Requip & Ropinirole hydrochloride & $2,494,428$ & & & discontinued \\
\hline Astagraf & Tacrolimus & $1,980,348$ & Propulsid & Cisapride monohydrate & NA; branded evergreened \\
\hline Xanax & Alprazolam & $1,791,458$ & 170pusist & & reformulation \\
\hline Allegra & Fexofenadine hydrochloride & $1,703,796$ & & & discontinued \\
\hline Glucotrol & Glipizide & $1,582,583$ & Proventil & Albuterol sulfate & NA; branded evergreened \\
\hline Dynacirc & Isradipine & $1,542,617$ & & & reformulation \\
\hline Sanctura & Trospium chloride & 985,378 & & & discontinued \\
\hline $\begin{array}{l}\text { Actoplus } \\
\text { MET }\end{array}$ & $\begin{array}{l}\text { Metformin hydrochloride; pioglitazone } \\
\text { hydrochloride }\end{array}$ & 920,083 & Etodolac & Etodolac & $\begin{array}{l}\text { NA; branded evergreened } \\
\text { reformulation }\end{array}$ \\
\hline Remeron & Mirtazapine & 818,186 & & & discontinued \\
\hline Lescol & \begin{tabular}{|l|} 
Fluvastatin sodium \\
\end{tabular} & 686,967 & Oruvail & Ketoprofen & NA; branded evergreened \\
\hline Biaxin & Clarithromycin & 618,906 & & & reformulation \\
\hline Flagyl & Metronidazole & 468,723 & & & discontinued \\
\hline Klonopin & Clonazepam & 324,186 & Zerit & Stavudine & NA; branded evergreened \\
\hline Aricept & Donepezil hydrochloride & 188,142 & & & $\begin{array}{l}\text { reformulation } \\
\text { discontinued }\end{array}$ \\
\hline Cardura & Doxazosin mesylate & 165,266 & & & \\
\hline Sinemet & Carbidopa; levodopa & 80,315 & Minipress & Prazosin hydrochloride & reformulation \\
\hline Atelvia & Risedronate sodium & 60,862 & & & discontinued \\
\hline Zomig & Zolmitriptan & 54,423 & Raniclor & Cefaclor & NA; branded evergreened \\
\hline Clarinex & Desloratadine & 43,797 & Naniticior & Ceractor & reformulation \\
\hline Razadyne & Galantamine hydrobromide & 18,821 & & & discontinued \\
\hline Naprosyn & Naproxen & 17,126 & Reglan & Metoclopramide hydrochloride & NA; branded evergreened \\
\hline Cardene & Nicardipine hydrochloride & 2,600 & & & reformulation discontinued \\
\hline $\begin{array}{l}\text { cludes } 2 \\
9,712,8 \\
=\text { not af }\end{array}$ & $\begin{array}{l}\text { ed reformulations, Abilify ODT (or } \\
\text { e savings when limited to Opana EF }\end{array}$ & rating tablet) & Aa & (extended-release injection). & \\
\hline
\end{tabular}

